Portland State University

PDXScholar

\title{
In Peer Matters, Teachers Matter: Peer Group Influences on Students' Engagement Depend on Teacher Involvement
}

Justin W. Vollet

Portland State University

Thomas A. Kindermann

Portland State University, kindermannt@pdx.edu

Ellen A. Skinner

Portland State University, ellen.skinner@pdx.edu

Follow this and additional works at: https://pdxscholar.library.pdx.edu/psy_fac

Part of the Educational Psychology Commons

Let us know how access to this document benefits you.

\section{Citation Details}

Vollet, Justin W.; Kindermann, Thomas A.; and Skinner, Ellen A., "In Peer Matters, Teachers Matter: Peer Group Influences on Students' Engagement Depend on Teacher Involvement" (2017). Psychology Faculty Publications and Presentations. 110.

https://pdxscholar.library.pdx.edu/psy_fac/110

This Post-Print is brought to you for free and open access. It has been accepted for inclusion in Psychology Faculty Publications and Presentations by an authorized administrator of PDXScholar. Please contact us if we can make this document more accessible: pdxscholar@pdx.edu. 
Running head: PEER INFLUENCE ON STUDENT ENGAGEMENT

In Peer Matters, Teachers Matter:

Peer Group Influences on Students' Engagement Depend on Teacher Involvement

Justin W. Vollet, Thomas A. Kindermann, \& Ellen A. Skinner

Portland State University

Correspondence concerning this article should be addressed to Justin Vollet, Department of Psychology, P.O. Box 751, Portland State University, Portland, OR 97207-0751. Electronic mail may be sent to jwv@pdx.edu.

This article may not exactly replicate the authoritative document published in the Journal of Educational Psychology. It is not the copy of record. 


\begin{abstract}
This study focused on the joint effects of teachers and peer groups as predictors of change in students' engagement during the first year of middle school, when the importance of peer relationships normatively increases and the quality of teacher-student relationships typically declines. To explore cumulative and contextualized joint effects, the study utilized three sources of information about an entire cohort of 366 sixth graders in a small town: Peer groups were identified using socio-cognitive mapping; students reported on teacher involvement; and teachers reported on each student's engagement. Consistent with models of cumulative effects, peer group engagement and teacher involvement each uniquely predicted changes in students' engagement. Consistent with contextualized models suggesting differential susceptibility, peer group engagement was a more pronounced predictor of changes in engagement for students who experienced relatively low involvement from teachers. These peer effects were positive or negative depending on the engagement versus disaffection of each student's peer group. Personcentered analyses also revealed cumulative and contextualized effects. Most engaged were students who experienced support from both social partners; steepest engagement declines were found when students affiliated with disaffected peers and also experienced teachers as relatively uninvolved. High teacher involvement partially protected students from the motivational costs of affiliating with disaffected peers, and belonging to engaged peer groups partially buffered students' engagement from the effects of low teacher involvement. These findings suggest that, although peer groups and teachers are each important individually, a complete understanding of their contributions to students' engagement requires the examination of their joint effects.
\end{abstract} Keywords: Student Engagement, Peer Influence, Teacher Influence, Differential Susceptibility, Joint Effects 
In Peer Matters, Teachers Matter:

Peer Group Influences on Students' Engagement Depend on Teacher Involvement

The construct of academic engagement has sparked considerable enthusiasm in both research and educational communities in recent decades for three reasons. First, engagement is a robust predictor of academic success, showing links to students' learning (Blondal \& Adalbjarnardottir, 2012), retention and graduation (Finn, 1989), and educational achievement and attainment (Finn \& Zimmer, 2012), across all educational grade levels (Hughes \& Kwok, 2007; Shernoff, Csikszentmihalyi, Schneider, \& Shernoff, 2003; Skinner, Kindermann, Connell, \& Wellborn, 2009; Ullah \& Wilson, 2007). Second, engagement seems to offer some protection from developmentally risky behaviors, such as drop-out and delinquency (Fall \& Roberts, 2012; Li \& Lerner, 2011; Wang \& Fredricks, 2014; Wang \& Peck, 2013), especially during early and middle adolescence, when these behaviors are otherwise normatively on the rise. And third, studies indicate that engagement is malleable and so open to intervention efforts (e.g., Anderson, Christianson, Sinclair, \& Lehr, 2004).

In recent years, a fourth source of enthusiasm about the construct of engagement has emerged, as motivational researchers have begun to explore the overlap between engagement, a construct grounded in educational, psychological, and sociological traditions targeting antidotes to student drop-out (Finn, 1989; Newmann, 1992; Rumberger \& Rotermund, 2012), and research on achievement motivation, an area of study grounded in the older and broader field of motivation (Deci, 1992; Weiner, 1990). Leaders in the field have recently suggested that student engagement may be considered an outcome of motivation and, as a result, research on 
engagement is now included in definitive reviews of motivational research (e.g.,

Wentzel \& Miele, 2016; Wigfield et al., 2015). Some motivational theorists even argue that classroom engagement, defined as students' ongoing, active, and energized participation in academic tasks, is a potential marker of a motivated state, and so can be considered an observable manifestation of the energy and persistence generated by underlying motivation (Ryan \& Deci, 2009; Skinner et al., 2009; Wang \& Degol, 2014). Viewing engagement from a motivational perspective opens up the possibility that many of the factors already established as important predictors of motivational development may also serve to support students' classroom engagement (Reeve, 2012; Skinner, 2016; Wang \& Eccles, 2012).

In fact, much of the research examining the ways in which students' engagement can be shaped by their interpersonal relationships in school has relied on motivational accounts of the influences of teachers and peers (Martin \& Dowson, 2009; Wentzel, 2009a, 2009b). To date, studies have largely concentrated on the role of teachers (Quin, in press; Roeser, Eccles, \& Sameroff, 2000; Wentzel, 1997), but in recent years, research has begun to expand to include friends, classmates, and peer groups (Wentzel \& Ramani, 2016). Up until now, however, few studies have looped back to examine the role of peer groups in combination with students' relationships with teachers, despite previous work that documents the centrality of teachers to student motivation and engagement (Quin, in press; Wentzel, 2009a). Guided by ecological models of schools as complex social systems, (Bronfenbrenner \& Morris, 2006), the purpose of the current study was to provide a more contextualized view of peer group contributions to academic engagement, by considering how their impact could be shaped by students' relationships with teachers, specifically, students' experiences of their teachers' involvement. 
PEER INFLUENCE ON STUDENT ENGAGEMENT

\section{A Social-Ecological Model of the Impact of Teachers and Peers on Student}

\section{Engagement}

The present study was framed by an ecological perspective. This framework suggests that complex social ecologies, like schools, can be conceptualized as multifaceted systems that contain multiple subsystems, and these subsystems work together to shape student development. If peer groups represent one such subsystem and teacher-student relationships represent a second, then an ecological perspective suggests that it may be important to examine them jointly, and posits two primary ways in which they can work together. First, teachers and peer groups may exert "cumulative" or additive influences, in which the contributions of social partners accrue in their effects and in which, despite some overlap, each may provide essential supports that the other cannot. Second, the influences of teachers and peer groups may be "contextualized" or interactive, in that the impact of one set of social partners may depend on the nature of the other. Many kinds of contextualized interactions among subsystems can be imagined, such as compensatory effects, in which support from one social partner protects students from the negative impact of the other, or amplifying effects, in which the positive or negative attributes of one social partner magnify the corresponding positive or negative effects of the other. Such a perspective suggests that the effects of peer groups may be both cumulative and contextualized - peers not only provide unique supports to academic engagement, but their effects also depend on the quality of students' relationships with teachers. Although an ecological perspective highlights the possibility of joint effects of teachers and peers, it does not specify how and why teacher involvement might temper the influence of peer groups. For guidance on these more specific questions, we turned to Self-Determination Theory (SDT; 
Connell \& Wellborn, 1991; Deci \& Ryan, 1985) and theories of Stage-Environment Fit (SEF; Eccles et al., 1993; Eccles \& Roeser, 2009).

Teacher involvement and student engagement. SDT posits that all people, including students in classrooms, have fundamental psychological needs for relatedness, competence, and autonomy. When those needs are fulfilled by participation in an enterprise, like school, individuals will more constructively take part in the activities of that enterprise, for example, students will engage more fully with learning activities in classrooms and cooperate more willingly with school rules (Ryan \& Deci, 2009). Consistent with this theory, decades of research have shown that students evince greater engagement when teachers provide higher levels of support for students' motivational needs, including warmth, pedagogical caring (Wentzel, 1997), closeness (Hamre \& Pianta, 2001), acceptance (Wentzel, 1994), help, direction (Ryan \& Shin, 2011), involvement, provision of structure, and autonomy support (Klem \& Connell, 2004; Skinner \& Belmont, 1993; see Quin, in press, for a review). A primary pathway through which teacher motivational support shapes engagement is by helping students feel more efficacious, autonomous, welcome, and safe, and to better internalize educational values (Connell \& Wellborn, 1991; Deci \& Ryan, 1985; Reeve, 2012; Skinner \& Belmont, 1993; Wentzel, 1999, 2009a; Wigfield et al., 2015).

Although studies have identified a wide band of teacher behaviors that promote student motivation and engagement, research suggests that central among them is teacher provision of pedagogical caring (Wentzel, 1997) or involvement (Skinner \& Belmont, 1993), which focuses on a constellation of teacher behaviors, including warmth, affection, and enjoyment, that mark a close and caring teacher-student relationship. One pathway through which teacher involvement 
seems to support student motivation and engagement is by fostering students' sense of belonging (Osterman, 2000; Goodenow, 1993), relatedness (Furrer \& Skinner, 2003), or attachment to school (Libbey, 2004). According to SDT, relatedness to teachers (and other social partners) acts like "psychological glue" that connects students to school and promotes their engagement. From this perspective, high quality student-teacher relationships, characterized by involvement and affection, are a foundation upon which the development of motivation and engagement depend (Eccles \& Roeser, 2009; Reeve, 2012; Wentzel, 2009a; Wigfield et al., 2015).

At the same time, SEF alerts researchers to the importance of early adolescence and the transition to middle school as a time when students' needs for relatedness may become increasingly strained. Just when young adolescents are testing their fledgling independence from parents by reaching out for closer connections to peers and adults outside the home, like teachers, the quality of students' relationships with teachers begins to decline (according to reports from both students and teachers; Wigfield et al, 2015). These declines may be due at least in part to organizational changes in which students shift from having few to many teachers per day, making it more difficult to build close connections (Eccles \& Roeser, 2009). SEF highlights this stage-environment mismatch, and suggests that declines in the quality of teacher-student relationships, which parallel declines in student engagement, may be a major contributor to losses in engagement and motivation over the transition to middle school (Eccles \& Roeser, 2009; Wigfield et al., 2015). Because of its centrality in promoting student motivation and its well documented decline at the middle school transition, the current study focused on the role of teacher involvement, specifically, students' experiences of their teachers as involved 
(affectionate, caring, and dependable) as a potential predictor of students' engagement in the classroom.

Challenges to examining teachers' involvement. While studies converge on the importance of teacher involvement to student engagement and motivation, researchers who aim to assess teachers' influence during middle school still face distinct challenges (Wentzel, 2009a). Although the identification of students' teachers may be straightforward, identifying those teachers who are best positioned to influence students' engagement is not. This is a particularly thorny issue for research in middle schools, where students interact with multiple teachers throughout the day. To overcome this problem, many researchers use measures that assess students' experiences of their teachers in general (e.g., Wang \& Eccles, 2012), thereby allowing students themselves to aggregate the most salient influences. In support of this practice, researchers have used questionnaires tapping students' perceptions of teacher involvement that include the stem "My teacher..." in longitudinal studies from elementary school through middle school (e.g., De Laet, et al., 2015; Skinner \& Belmont, 1993). Evidence of the functioning of these scores over time indicates that, at least under these conditions, such measures maintain their key psychometric and validity characteristics (Skinner, Kindermann, \& Furrer, 2008; Skinner, Zimmer-Gembeck \& Connell, 1998).

Peer groups and student engagement. Multiple strands of research have converged on the conclusion that classmates and friends also play a significant role in student motivation and engagement in school (Wentzel, 2009b). Although much of this research has focused on close, reciprocated friendships as sources of enjoyment and correlates of success in school (Altermatt \& Pomerantz, 2005; Berndt, Hawkins, \& Jiao, 1999; Hallinan \& Williams, 1990; Ladd, 1990), a 
growing number of studies have examined the role of naturally-occurring peer groups.

This work explores the proposition that one way peers influence student engagement, motivation, and achievement is through proximal processes that occur in frequent social interactions within self-selected groups of peers (Kindermann, 2007; Ryan, 2000, 2001). A key idea is that participation in groups of peers who are engaged or disaffected from school has the potential, in addition to the contributions of friendship relationships and dyadic interactions with peers, to impact students' own emotional and behavioral engagement in the classroom (Kindermann \& Skinner, 2012). Theories of peer group influence have suggested that their effects may be conveyed through multiple channels. They may be transmitted directly, through mechanisms of socialization, including modeling, reinforcement, encouragement, or pressure to conform to group norms (Altermatt \& Pomerantz, 2005; Harris, 1995; Kindermann, 2003; Lynch, Lerner, \& Leventhal, 2013), as well as indirectly, for example, by fulfilling needs for relatedness (Anderman \& Anderman, 1999; Nelson \& DeBacker, 2008; Furrer \& Skinner, 2003) or providing academic help and support (Lempers \& Clark-Lempers, 1992; Wentzel \& Watkins, 2011).

Peer groups, which can be viewed as largely self-selected social contexts, provide opportunities for dyadic interactions and the formation of friendship relationships with similar peers (Kindermann \& Skinner, 2012). Because peer groups tend to be selected based on similarity (i.e., homophily), such groups can create a more concentrated or intensified local context, that, in the case of engagement and disaffection, may surround students who are already engaged with a higher concentration of engaged peers, and expose students who are already somewhat disaffected to a higher concentration of disaffected peers, thus potentially amplifying 
individuals' initial motivational states over time. For example, studies have shown that peer groups' average engagement levels at the beginning of the school year are small but robust predictors of changes in students' teacher-reported engagement over the year, during both elementary and middle school (Kindermann, 1993, 2007). In the same vein, Ryan (2001) found that middle school students who affiliated with peers who disliked school showed the steepest declines in their own enjoyment of school. Because of their potential importance to the development of students' engagement, the current study focused on the role of peer groups, specifically, the extent to which the members of an individual student's peer group were engaged versus disaffected with academic activities in the classroom.

Challenges to the study peer groups. While a growing number of studies have pointed to the important role peer groups play in the development of student engagement and motivation, they have also highlighted two key challenges to investigating their effects. First, it can be difficult to reliably identify children's peer groups in naturalistic contexts, like schools. Natural peer groups consist of the agemates with whom children regularly interact. Such groups are hard to define because they are self-organized, evolve rapidly, and are often overlapping. To address this challenge, the current study used Socio-Cognitive Mapping (SCM; Cairns, Perrin, \& Cairns, 1985), which employs students themselves as expert observers of group interactions. Because students have the opportunity to witness schoolmates' public exchanges every day, such "insider" observations afford the most complete access to information about naturally occurring peer groups. Another advantage of relying on multiple observers is that it allows for an assessment of the level of agreement between reporters. Furthermore, unlike self-reports, which require near complete participation (otherwise each non-participating child is also missing as a 
potential peer group member of participating children), the accuracy of SCM is less affected by participation rates, because other reporters typically include missing group members. In fact, Cairns and Cairns (1994) estimated a criterion such that, when the sample of reporters is relatively representative, reports from slightly more than half the student body are sufficient to yield reliable networks.

Once the members of each student's peer groups have been identified, a second challenge is to figure out how to capture meaningful characteristics of groups. One method, used in the present study, is to create peer profile scores for each child, by identifying the members of a target child's peer group, and then combining measures of key characteristics obtained for each member (Kindermann, 1993; 1996; Kurdek \& Sinclair, 2000; Ryan, 2001). Peer profiles of engagement can be calculated for a given student by averaging the engagement scores of each member of his or her peer group. In the current study, SCM was used to identify the members of each child's peer groups, and peer profiles of engagement versus disaffection were used to capture the motivational composition of each child's local peer context, with the expectation that these profiles might predict changes in individual student's engagement over the school year.

\section{Studies of Joint Effects of Teachers and Peers}

As research on peer group influences has begun to accumulate, findings seem to converge on their potential importance to student motivation and engagement (Wentzel \& Muenks, 2016). However, few of these studies have tried to incorporate the impact of the other major social partner in the classroom, namely, teachers. To date, only seven studies have examined the joint effects of teachers and peers on student academic engagement, motivation, or success. To guide our own examination of the interplay between teachers and peers, we built on the few studies 
that have begun to incorporate the effects of both social partners, looking carefully at the attributes they targeted and how they analyzed different configurations of these relationships.

Evidence for cumulative effects. Of the seven studies of joint effects, four found evidence for only cumulative effects, in which peers contributed uniquely to student engagement over and above the effect of teachers. In a large sample of 13-year-old students in Norway, Danielsen, Wiium, Wilhelmsen, and Wold (2010) found that perceptions of support from teachers (i.e., friendliness and fairness) and peers (i.e., classmates' acceptance, kindness and helpfulness, and sense of togetherness) each uniquely predicted students' self-reported academic initiative (tapped using items such as "I challenge myself when I am doing schoolwork") at the individual level; interactions were not examined. In a second study, Wentzel, Battle, Russell, and Looney (2010) analyzed the extent to which middle schoolers' perceptions of four kinds of supports from teachers and peers (expectations for academic engagement and positive social behavior, provisions of help, safety, and emotional nurturing) were related to school motivation. Multiple regressions, controlling for sex, grade level, and teacher, revealed that all four of the teacher supports uniquely predicted student self-reported academic motivation. When peer supports were entered in the last step, both peer expectations and help were also unique predictors, although none of the interactions between corresponding teacher and peer supports were significant.

In a third study, De Laet and colleagues (2015) investigated whether relationship qualities of teachers (including global support and conflict) and peers (including popularity and acceptance) jointly predicted the development of children's behavioral engagement from grades 4 to 6 . An additive model showed the best fit to the data, indicating that high and increasing 
levels of teacher support and high levels of peer acceptance (but not teacher conflict or peer popularity) contributed independently to counteract the normative declines in children's behavioral engagement. Analyses of moderation and mediation were conducted but none were found. In a fourth study, Wang and Eccles (2012) examined growth curves of behavioral, emotional, and cognitive engagement from grades 7 to 11 , which they assessed using studentreports of school compliance, identification with school, and subjective value of learning, respectively. Although, in general, all three dimensions of engagement showed the normative declines typical for these ages/grades, students' reports of peer support predicted more favorable trajectories, that is, less steep declines, over and above the effects of support from teachers (and parents). No two-way interactions with support from teachers (or parents) qualified the protective contributions of peer support, but these effects were more pronounced for the trajectories of emotional and cognitive engagement of African-American students. Moreover, protective effects of peer support on behavioral engagement were found only for students who reported having more pro-social friends. For students reporting more anti-social friends, higher levels of peer support actually exacerbated declines in engagement.

Evidence for contextualized effects. Three additional studies found evidence for both cumulative and contextualized effects. All three used either pattern-oriented or person-centered analyses to examine groups of students who differed in their profiles of relationships with peers and teachers. In an early study, Furrer and Skinner (2003) examined third through sixth grade students' reports of their relatedness to teachers and peers (as well as parents) as predictors of self- and teacher-reported behavioral and emotional engagement. Using median splits, they created groups of students with high relatedness to none, one, two, or all three of these social 
partners. Group comparisons revealed that high relatedness to teachers could compensate for low relatedness to peers, but high relatedness to peers could not compensate for low relatedness to teachers. In a second study, Davidson and colleagues (2010) focused on school adjustment as the target outcome (assessed as an aggregate of academic skills and selfconcept, school bonding, loneliness, and self-worth), and used latent profile analysis to identify students with different patterns of relatedness to teachers and peers (based on teacher-reported teacher-student closeness, peer-nominated peer social preference, and self-reports of perceived peer competence). Three groups were distinguished: (1) high relatedness (high on all three indicators); (2) low relatedness (low on all three indicators); and (3) peer-oriented (medium teacher-student closeness combined with high peer social preference and perceived peer competence). Although adjustment was lowest for students who reported low relatedness to both peers and teachers at the beginning of the sixth grade, students from both high relatedness and peer-oriented groups evinced positive academic adjustment, suggesting that positive relationships with peers might be sufficient to support adjustment, even without highly supportive relationships with teachers. Finally, Raufelder, Jagenow, Drury, and Hoferichter (2013) used latent class analysis to identify four groups of students, namely, those who reported that their academic motivation was more dependent on teachers, more dependent on peers, dependent on both, or dependent on neither. Interestingly, the largest group of students consisted of those who saw their academic motivation as primarily dependent on peers, followed by students who saw their motivation as simultaneously peer- and teacher-dependent. Degree of membership in all four clusters was associated with several markers of motivation, including academic drive, learning goals, striving for academic success, and avoidance of academic failure. 
PEER INFLUENCE ON STUDENT ENGAGEMENT

Critique of current studies of joint effects of peers and teachers. Taken

together, these studies provide evidence for two complementary perspectives on how teachers and peers work together to shape students' academic engagement, motivation, and adjustment. On the one hand, all seven found evidence of cumulative effects of peers and teachers, whether studies used variable-centered (Danielsen et al., 2010; De Laet et al., 2015; Wang \& Eccles, 2012; Wentzel et al., 2010) or person-centered analyses (Davidson et al., 2010; Furrer \& Skinner, 2003; Raufelder et al., 2013), suggesting that peers play an important role in their own right, a role not completely filled by teachers, no matter how much support they provide. However, studies did not converge on whether joint effects are also contextualized, that is, whether peer group effects are qualified to some extent by students' relationships with their teachers. In fact, three studies explicitly tested for interactions, but did not find them (De Laet et al., 2015; Wang \& Eccles, 2012; Wentzel et al., 2010). In trying to explain these differences, it may be significant that, in two of these three studies (Wang \& Eccles, 2012; Wentzel et al., 2010), researchers relied on student-report measures to tap all three of the key constructs, namely, teacher support, peer support, and motivational outcomes. It is possible that commonmethod variance makes it more difficult to disentangle the differential effects of the three parties involved. In the current study, information about each player was provided by separate sources. Such separation may facilitate the detection of these more complex interactive effects. Consistent with this notion, other studies that employed multiple independent reporters also uncovered interactive effects (e.g., Davidson et al., 2010).

A second factor contributing to differing patterns of results in previous studies could be the specific characteristics of teachers and peers that researchers targeted for investigation. 
Studies were relatively consistent in their selection of teacher factors. All seven studies focused on the social-emotional qualities of student-teacher relationships that have been shown to predict student motivation and engagement (such as involvement, closeness, friendliness, fairness, positive expectations, and provision of help, safety, and emotional nurturing; Sabol \& Pianta, 2012; Wentzel, 2009a). However, studies varied widely in the peer attributes they targeted. Some included student ratings of general support from peers and teachers (Wang \& Eccles, 2012) or feelings of relatedness to both partners (Furrer \& Skinner, 2003). Some examined specific qualities of peer relationships that were strictly parallel to those examined in teachers (e.g., Wentzel et al, 2010). Other studies selected peer characteristics that were not exactly the same as those of teachers, but were also in the general domain of social-emotional relationship qualities (i.e., classmates' acceptance, kindness, helpfulness, and togetherness; Danielsen et al., 2010). Finally, some researchers focused on key markers of overall positive functioning in the peer domain, such as peer-nominated popularity, acceptance, or social preference (De Laet et al., 2015; Davidson et al., 2010).

In the current study, consistent with other researchers of joint effects, we examined the social emotional quality of students' relationships with teachers as predictors of their engagement. However, we differed from all previous studies in the peer characteristics we decided to target. Instead of examining peer relatedness or peer support, which have been the focus of previous studies, we targeted the engagement profiles of students' naturally-occurring peer groups. We reasoned that, unlike teachers, peers do not typically have the goal of promoting a student's motivation, so their efficacy may not reside in the quality of their relationships or the support they provide. Instead, peers may shape engagement through the power of joint activity, 
that is, students' own engagement may be buoyed by participating as an active member of a group of enthusiastically engaged age-mates who enjoy and work hard at learning activities. In contrast, trying to complete learning activities within local contexts of disaffected peers who may be passive, bored, frustrated, or discouraged can exert a downward pressure on students' own engagement, and so eventually reinforce or intensify their own disaffection.

\section{The Interplay of Teacher and Peer Group Influences in School}

The current study attempted to build on previous studies of joint effects, integrating them using an ecological framework focused on motivational theories, and strengthening them by employing key strategies to meet the methodological challenges of studying peer groups and teacher involvement. As the target outcome, we focused on changes in sixth-graders' engagement over the school year, since middle school marks a time when peer relationships normatively increase in importance and the quality of teacher-student relationships typically declines (Wigfield et al., 2015).

Consistent with previous research, we expected to find joint effects that were both cumulative and contextualized. We focused on one specific pattern of contextualized effects, referred to as differential susceptibility, in which student receptiveness to peer group influences is more or less pronounced, depending on the quality of their involvement with teachers. Following SDT and SEF, we reasoned that, if after the transition to middle school, students are not able to establish warm and supportive relationships with teachers, they might become less adult-oriented and more open to peer group influences (Davidson, Gest, \& Welsh, 2010), thus amplifying the impact of peers. If so, then low teacher involvement during this developmental period could render students more susceptible to the impact of their peer groups, which would be 
especially problematic for students who hang out with disaffected peers. In contrast, high teacher involvement might be able to protect students from some of the motivational costs of belonging to disaffected peer groups.

To conduct this investigation, we relied on a data set that contained all of the elements needed to examine joint effects, that is, a data set that incorporated different sources of information about each of the key constructs, in this case, information about peer groups derived from multiple peer-observers, ratings of student engagement from teachers, and students' ratings of their experiences of the involvement provided by their teacher (Kindermann, 2007). Although peer group contributions to student engagement, through processes of selection and socialization, have been documented in this data set, no previous attempts have been made to determine whether the magnitude of these effects differs for students who experience differing levels of teacher involvement. In some ways, the current study may be seen as encouragement to researchers who have previously examined the contributions of peers or teachers separately, to revisit their data sets to see if information about the other social partner is available, and so would allow a more ecologically-oriented examination of their joint effects on student engagement, motivation, or adjustment.

We investigated patterns of joint influence in three steps. First, we examined the possibility of cumulative effects, in which teachers and peer groups make largely separate and additive contributions to students' developing academic engagement. To test this model, we first replicated the general finding that teacher involvement and peer group profiles of engagement each positively predicts changes in student engagement individually, and then examined whether they make additive contributions. We expected that peer groups would make a unique 
contribution, over and above the contribution of teacher involvement. Second, we investigated the possibility of contextualized effects. Consistent with the notion of differential susceptibility, we expected that peer groups would play a more prominent role in predicting changes in students' engagement when teachers were less involved. Based on research suggesting that peer groups can socialize towards engagement or towards disaffection (Kindermann, 2007; Ryan, 2001; Wang \& Eccles, 2012), we expected that these more pronounced peer group contributions would be positive or negative depending on the profile of engagement versus disaffection characterizing each child's peer group, with students who affiliated with engaged peers groups showing increases in engagement and those affiliating with disaffected groups showing declines over the school year.

Third, we explored patterns that included both cumulative and contextualized effects, using latent profile analysis to identify groups of students who showed different combinations of teacher involvement and peer group engagement. We then examined whether these clusters of students showed different patterns of change in their academic engagement over the year. We expected to see two specific patterns. First, we predicted cumulative effects: It was expected that neither having an involved teacher alone nor affiliating with engaged peers alone would be sufficient to foster optimal levels of student engagement. To optimize engagement, students would likely require both involved teachers and engaged peer groups. If so, then students with the highest levels of engagement over the year would be those who both affiliated with engaged peers and experienced high levels of teacher involvement, whereas the steepest declines would be found among students who not only affiliated with disaffected peers, but also experienced their teachers as uninvolved. Second, we also expected contextualized effects, such that high 
teacher involvement would protect children from some of the motivational costs of affiliating with disaffected peer groups (Sabol \& Pianta, 2012), and by the same token, connections with engaged peers would buffer students from the motivational costs of experiencing uninvolved teachers.

\section{Method}

For this study, Kindermann's (2007) dataset was reanalyzed. Of 366 sixth-grade students (age 11-13) enrolled at the sole middle school (grades 6 through 8) in a small rural/suburban town in the U.S., 340 (93\%) participated; all of them had been participants in a longitudinal study since 3rd grade. Most students identified themselves as Caucasian, with less than 5\% identifying themselves as non-white, and were predominately from working to middle class families ( $87 \%$ of the adult population had at least a high school degree). The number of male and female participants was roughly equivalent ( $48 \%$ female).

The middle school these sixth graders attended was organized around homeroom classes: Students were assigned to these structured 20-minute first-period classes for the whole year. This arrangement was explicitly designed to provide homeroom teachers with the opportunity to get to know their students by checking in and interacting with them every day. Although homeroom teachers taught varying subjects (and so saw most of their students again in content classes), they were expected to serve as supports for their homeroom students and as designated liaisons to other teachers if students experienced academic or behavioral problems. All 13 of the sixth-grade homeroom teachers participated in the current study. They provided information about the students in their homeroom classes, and indicated that they knew their students very well and were familiar with their academic problems and progress. Questionnaires were administered to 
students in class by trained interviewers; items were read aloud by one interviewer, while a second interviewer monitored the classroom to answer individual students' questions. Teachers were not present in the classroom, and typically completed their questionnaires during this time.

\section{Students' Academic Engagement}

Students' academic engagement was assessed using a 14-item Likert-type scale measuring teachers' perceptions of students' engagement in academic activities (Wellborn, 1992). These measures are not intended to measure engagement in a single classroom, but in classrooms in general. The scale assesses students' behavioral engagement (e.g., "This student works as hard as he/she can") and emotional engagement (e.g., "In my class, this student appears happy"). Prior studies on fourth through seventh graders have shown moderate to strong intercorrelations between the components $(r=.72, n=1,018$; Skinner et al., 2008) and indicated that they form an internally consistent indicator of engagement $(\alpha=.90, n=1,018)$. Teacher reports of engagement have been found to be stable over time $(r=.73, p<.001, n=144$, Wellborn, 1992; $r=.78, p<.001, n=1,018$, Skinner et al., 2008) and moderately correlated with academic achievement in the expected direction $(r=.40$ with math achievement, $r=.58$ with reading achievement, Skinner \& Belmont, 1993; Skinner et al., 1990).

Teacher perceptions of student engagement were obtained at two time points during the school year, first in October and then again in May. At the first time point, homeroom teachers reported on 318 students ( $93 \%$ of the consenting students; $87 \%$ of the population). At the second time point, homeroom teachers reported on 322 students. Missing data and differences in sample size at the two measurement points are due to a combination of student attrition and new students 
entering the school. Three hundred students had teacher reports at both time points.

\section{Naturally Occurring Peer Groups}

In October, students reported on naturally occurring peer groups using Social Cognitive Mapping (SCM; Cairns et al., 1985). In SCM, participants serve as "expert observers," reporting on whom they frequently see "hanging around" together while at or away from school. Students were provided with a form containing space for observations of up to twenty groups, each group having space for up to twenty members. Of the 280 participating students ( $77 \%$ of the sample; $56 \%$ female), none exhausted the space provided. Students were encouraged to consider all students in their entire school, regardless of grade level, as well as peers from outside the school. They were asked to list as many groups as they could from free recall, and were instructed to include dyadic groups as well as their own groups. Students could be nominated as being members of many separate groups at the same time so that multiple and overlapping groups were retained.

Peer groups were identified by first arranging students' reports of groups in a cooccurrence matrix, indicating the frequency with which each student was observed in interactions with each other student. Binomial z-scores were calculated for each co-occurrence in the matrix, and a $1 \%$ significance level was used to determine whether a student was more likely to be nominated as being in a group with each other student than could be expected by chance (for details, see Kindermann, 2007). In order to guard against self-enhancement biases, significant connections that were based on one single observation were not accepted, as in almost all cases these were children's own self-nominations. Not counting errors of omission (e.g., that most girls do not report most boys' peer groups), there was high consensus about group 
connections $(k a p p a=.88)$.

Three key indices of the characteristics of peer group networks were calculated. The number of members, excluding the focal student, who were identified in each student's peer group was used as a measure of group size. The percentage of peers maintained as group members from fall to spring was taken as an indicator of peer group stability. Finally, peer group profiles of engagement were calculated by averaging the teacher-rated engagement scores across the members of each child's group connections.

\section{Teacher Involvement}

In October, students themselves reported on the amount of involvement experienced from their teachers by responding to 11 items (Skinner \& Belmont, 1993; all items were on a 4-point scale). The scale captures three facets of teacher involvement: the extent to which students' teachers showed affection (three items; e.g., "My teacher really cares about me"), the extent of availability (three items; e.g., "My teacher is always there for me"), and the extent of dependability (five items; e.g., "I can rely on my teacher to be there when I need him/her"). Because the students had been involved in the longitudinal study from third grade onwards, teacher involvement items were worded so that they referred to a single teacher. Thus, the items are used as a proxy for students' experiences of general teacher involvement. Previous work has found that these measures have high internal consistency $(\alpha=.79, n=144$, Skinner $\&$ Belmont, 1993) and that their key psychometric and validity characteristics are maintained from elementary to middle school (Skinner, et al., 2008; Skinner, et al., 1998).

\section{Results}

Descriptive statistics and correlations can be found in Table 1. In all analyses, a Full 
Information Maximum Likelihood method was used to estimate missing data. Overall, students showed moderate levels of engagement in both fall $(m=3.07, \mathrm{SD}=.57)$ and spring $(m$ $=3.07, \mathrm{SD}=.61)$, with relatively high stability between time points $(r=.75, p<.001)$. On average, members of students' peer groups were moderately engaged in fall $(m=3.09, S D=$ $.34)$, with larger groups showing a tendency toward higher engagement $(r=.25, p<.001)$. Peer groups were modest in size $(m=4.81, S D=3.99)$, and relatively stable across the school year, with just about half of students' affiliations in fall continuing into spring ( $m=.46, S D=.33)$. Finally, while students, on average, rated their teachers as being fairly involved $(m=3.01, S D=$ .52 ), students who experienced their teachers as more involved were more engaged themselves both in fall $(r=.34, p<.001)$ and in spring $(r=.40, p<.001)$, and tended to be affiliated with peers who were more engaged in fall $(r=.20, p<.001)$.

\section{Cumulative Effects: Do Peer Groups Contribute to Engagement Over and Above the Effects of Teachers?}

Cumulative effects of teachers and peers were examined in two steps. First, in analyses of each potential contributor separately, peer group engagement scores in fall were found to predict changes in students' engagement from fall to spring, $\beta=.11, p<.05 ; \chi^{2}(36)=60.250, p=.007$; $\mathrm{CMIN} / \mathrm{DF}=1.674, \mathrm{CFI}=.988, \mathrm{RMSEA}=.043$, as did teacher involvement, $\beta=.15, p<.01$; $\chi^{2}(39)=51.333, p=.089 ; \mathrm{CMIN} / \mathrm{DF}=1.316, \mathrm{CFI}=.993, \mathrm{RMSEA}=.029$. Both models controlled for sex, peer group stability, and peer group size. In a second set of analyses, the contributions of peer group engagement and teacher involvement were modeled simultaneously, again controlling for peer group size and stability, and sex. This model fit the data well, $\chi^{2}(66)=$ $101.358, p=.003, \mathrm{CMIN} / \mathrm{DF}=1.536, \mathrm{CFI}=.986, \mathrm{RMSEA}=.038$, and indicated that peer group 
engagement in fall predicted changes in students' engagement across the school year $(\beta$ $=.10, p<.05)$, over and above the contribution of teacher involvement $(\beta=.15, p<.01)$.

\section{Contextualized Effects: Do the Effects of Peers Differ for Students with Different Levels of}

\section{Teacher Involvement?}

In order to investigate differential susceptibility, in which students' experiences of teacher involvement can magnify or reduce the impact of their peer groups on academic engagement, data were analyzed using two complementary modeling strategies. First, a latent moderated model was used to examine whether peer group effects on changes in students' engagement depended on teacher involvement. Then, to aid the interpretation of the interaction, a multiple-group model examined whether peer group effects on students' academic engagement were significantly different between students who experienced highly involved teachers and students who experienced less involved teachers. Both modeling strategies used AMOS 19 (Arbuckle, 2010).

The moderated model (see Figure 1), which was tested using the orthoganilizing procedure described by Little, Bovaird, and Widaman (2006), showed good fit to the data, $\chi^{2}(203)=188.302, p=.763 ; \mathrm{CMIN} / \mathrm{DF}=.928, \mathrm{CFI}=1.000, \mathrm{RMSEA}=.000 \mathrm{C} . \mathrm{I} .=.000$ to .017 . As indicated by the model, the interaction between peer group engagement and teacher involvement was a significant predictor of changes in students' engagement from fall to spring ( $\beta$ $=-.15, p<.01)$, suggesting that peer group contributions to changes in students' academic engagement were dependent on students' experiences of involvement from their teachers. The negative interaction parameter indicates that lower teacher involvement was associated with 
increased peer effects.

Multiple-group SEM analyses further explored whether differences in the extent to which peer groups contributed to students' engagement could be found between students who experienced highly involved teachers versus students who experienced their teachers as less involved. Using a tertile split, two groups of nearly equivalent size were identified: students who perceived their teachers as most involved $(n=129, m$ involvement $=3.54)$, and students who perceived their teachers as least involved $(n=127, m$ involvement $=2.47 ; 100$ students in the middle range were omitted). Compared to students who experienced teachers as least involved, students of highly involved teachers were more engaged both in fall and spring, and affiliated with more engaged peers (see Table 2).

To test for differences in peer group effects between these groups, a 3-step model invariance procedure was used (Kline, 2011; Tabachnick \& Fidell, 2007). First, a configural model (Figure 2) was fit to the data, freely and simultaneously estimating model parameters for both groups. This model showed good fit to the data, $\chi^{2}(72)=96.454, p=.029 ; C M I N / D F=$ $1.340 ; C F I=.982 ; R M S E A=.038 ; 90 \%$ C.I. $=.013$ to .057 . Despite similarity between the two groups in terms of stability of individual engagement, peer group contributions to changes in student engagement were greater for students who perceived their teachers as less involved $(\beta=$ $.30, p<.001)$. By comparison, results indicated that no significant peer group effects were found among students who perceived their teachers as most involved $(\beta=-.05, p>.05)$.

To test the significance of this difference, cross-group equality constraints were imposed on the model, beginning with the factor loadings. Constraining the measurement portion of the model did not lead to significant reductions in model fit, $\Delta \chi^{2}(6)=5.548, p>.05$, indicating 
measurement equivalence between the two groups. The model fit the data well, $\chi^{2}(78)$ $=96.180, p=.080 ; C M I N / D F=1.233 ; C F I=.987 ; R M S E A=.030 ; 90 \%$ C.I. $=.000$ to .049. In a final step, the two-group model was estimated with an additional cross-group equality constraint imposed on the model parameter representing peer group effects on changes in students' engagement. Model fit remained good, $\chi^{2}(79)=102.337, p=.040 ; C M I N / D F=1.295 ; C F I=$ $.984 ;$ RMSEA $=.034 ; 90 \%$ C.I. $=.008$ to .052 ; however, the imposition of this constraint lead to a significant reduction in model fit, $\Delta \chi^{2}(1)=6.157, p<.05$, confirming the expectation that this parameter of the model should differ between groups. These results complement findings from the latent moderated model and support a contextualized view of peer influence on student engagement, suggesting that peer group contributions to students' engagement were greater among students who experienced their teachers as less involved.

\section{Cumulative and Contextualized Effects: Do Students with Different Configurations of Peer Group Engagement and Teacher Involvement Show Differential Change in Engagement?}

To explore cumulative and contextualized effects, that is, to examine whether the joint effects of teachers and peer groups can be additive and compensatory, data were analyzed using a person-centered approach. Specifically, groups of students were identified who had different combinations of peer and teacher contexts, and these groups were compared to see whether they differed in the way their engagement changed across the school year. For these analyses, types of students were identified from the entire sample using latent profile analysis (LPA) modeling using MPLUS version 7.2 (Muthén \& Muthén, 2012). Four separate LPA models were tested, with 2, 3, 4, or 5 profiles specified. All LPA model solutions were stopped at 60,000 iterations, and relative fit was assessed by comparing the Akaike Information Criterion (AIC), Bayesian 
Information Criterion (BIC), and the Sample Size-Adjusted Bayesian Information Criterion (Adj. BIC) for each model (see Table 3). With each of these assessments of fit, lower values indicate better model fit (Nylund, Asparouhov, \& Muthén, 2007). In addition to assessing relative model fit, model preference was also based on the presence of adequately-sized profile groupings, and whether groups fit well with theoretical expectations. While the 5-profile model showed the best fit (as assessed by AIC and Adj. BIC), one of the profile groupings identified was inadequately sized $(\mathrm{n}<10)$, and substantively indistinguishable from another profile grouping; thus, profiles identified using this model were not used. Profiles based on the 4-profile model were chosen for use in subsequent analyses, as this model showed the best fit (in comparison to all models but the 5-profile model), produced adequately-sized profile groupings, and aligned well with theoretical expectations for the variety of configurations represented. This model identified the following types of students: members of engaged peer groups $(m=3.35, S D$ $=.25)$ who experienced high teacher involvement $(m=3.52, S D=.30 ; n=132)$, members of engaged peer groups $(m=3.28, S D=.24)$ who experienced low teacher involvement $(m=2.56$, $S D=.32 ; n=107)$, members of disaffected peer groups $(m=2.74, S D=.20)$ who experienced high teacher involvement ( $m=3.08, S D=.33 ; n=94)$, and members of disaffected peer groups $(m=2.50, S D=.31)$ who experienced low teacher involvement $(m=2.21, S D=.41 ; n=33)$.

Changes in engagement across the school year are shown in Figure 3 for each of the four different types of students identified by LPA. An ANCOVA showed mean level-differences in student engagement between the four types of students in both fall, $F(3,359)=15.66, p<.001$, and spring, $F(3,359)=21.94, p<.001$, accounting for the covariates of sex, peer group size, and group stability. The strength of the relationship between cluster membership and student 
engagement in both fall $\left(\omega^{2}=.10\right)$ and spring $\left(\omega^{2}=.14\right)$ was moderate, accounting for the covariates. Post-hoc comparisons examined pairwise differences between the groups. As expected, the most engaged students were those who both affiliated with highly engaged peers and also experienced teachers as highly involved; these students showed the highest levels of engagement in both fall $(m=3.32, S D=.51)$ and spring $(m=3.34, S D=.55)$. They were more engaged than students who experienced only favorable teacher contexts $(m$ difference $=.33, p<$ .001 , in fall; $m$ difference $=.27, p<.001$, in spring), as well as students who experienced only favorable peer contexts $(m$ difference $=.31, p<.001$, in fall; $m$ difference $=.33, p<.001$, in spring). Conversely, the most disaffected students were those who both affiliated with disaffected peers and experienced teachers as least involved; these students showed the lowest levels of engagement in both fall $(m=2.62, S D=.62)$ and spring $(m=2.41, S D=.63)$. They were less engaged than students who experienced only favorable teacher contexts ( $m$ difference $=-.32, p<.01$, in fall; $m$ difference $=-.61, p<.001$, in spring), as well as students who experienced only favorable peer contexts $(m$ difference $=-.34, p<.01$, in fall; $m$ difference $=$ $.54, p<.001$, in spring). Together these results support an additive model of the joint contributions of peer groups and teachers to students' engagement: Although it was better to have either an engaged peer group or an involved teacher than having neither, for students to have the highest levels of engagement, support from both peers and teachers was needed.

Results from a repeated-measures ANCOVA also showed significant differences between the LPA-identified groups in how their engagement changed across the school year, $F(3,359)=$ $3.93, p<.01$. As predicted, students who experienced teacher and peer group contexts that were both favorable (i.e., having involved teachers and affiliating with engaged peer groups) fared 
best over time, showing high and stable engagement across the year $(\Delta m=.01), t(131)$

$=.40, p>.05$. In contrast, students with the least favorable contexts (i.e., who experienced the least involvement from their teachers and also affiliated with the most disaffected peers) demonstrated the steepest declines in engagement across the academic year $(\Delta m=-.21), t(40)=-$ $2.35 p<.05$. At the same time, evidence for partially compensatory effects was also found. Students who affiliated with disaffected peers, but who viewed their teachers as more involved evinced moderate levels of academic engagement (showing higher levels than the most disaffected group but lower levels than the most engaged group) that increased marginally ( $\Delta m=$ $.09)$ from fall to spring, $t(93)=1.91, p<.06$. This suggests that an involved teacher can offset some of the motivational costs of affiliating with disengaged peers. Similarly, students who viewed their teachers as less involved, but nevertheless affiliated with engaged peers also showed moderate levels of academic engagement that remained stable over the year $(\Delta m=-.01)$, $t(106)=-.38, n s$, suggesting that academically enthusiastic peer group members can protect against some of the motivational costs of experiencing teachers as unsupportive.

\section{Discussion}

In 1976, Urie Bronfenbrenner wrote “...the ecology of education is not and cannot be confined solely to conditions and events occurring within a single setting, such as home, school, peer group, workplace, etc.; equal emphasis must be given to relations obtaining between settings" (p. 12). If the notion of "contextualization" can be applied not only to settings, but also to interactions with social partners, this suggests that the nature of the interactions between two people in a given setting may be best understood in the context of the other interactions those two people have experienced in that setting. In that spirit, this study sought to contribute to an 
emerging body of work focused on the joint effects of teachers and peers by examining how these subsystems of the school social ecology work together, both independently and interdependently, to shape students' motivation to engage in learning activities.

More specifically, we tested whether models of cumulative (additive) and contextualized (interactive) joint effects could explain changes in students' engagement from fall to spring of their first year in middle school, when peer influences are on the rise and the quality of students' relationships with their teachers typically declines. Evidence was found for both kinds of effects. Consistent with prior studies (Kindermann, 2007; Ryan, 2001; Klem \& Connell, 2004; Wentzel, 1997), results from SEM models testing peer and teacher effects separately indicated that both peer group engagement and teacher involvement individually predict changes in student engagement over the school year. When tested simultaneously, peer groups were found to make a unique contribution to changes in students' engagement, over and above the substantial contribution of teacher involvement, suggesting that peers and teachers contribute uniquely to students' engagement, and that their effects may be cumulative.

At the same time, findings suggested that the effects of peer groups are also contextualized. Interactions between peer groups' engagement and teachers' involvement were significant as predictors of changes in students' own engagement, indicating that the motivational contribution of peer groups was magnified or reduced depending on students' experiences of involvement from their teachers. Consistent with the notion of differential susceptibility, tests of multi-group models showed that peer groups were significantly stronger as predictors of changes in engagement among students who perceived their teachers as less involved, with these more pronounced peer group effects associated with positive or negative 
consequences for engagement depending on the motivational composition of each child's peer group.

Person-centered analyses likewise revealed support for both cumulative and contextualized models. On the one hand, joint effects of peer groups and teachers were clearly cumulative. Neither teacher involvement nor peer group engagement alone were sufficient to foster the highest levels of student engagement; and declines in engagement were steepest for students who both affiliated with disaffected peers and reported lower levels of teacher involvement. On the other hand, results also suggested that teacher involvement could partially buffer students from the motivational costs of belonging to disaffected peer groups: Students who affiliated with disengaged peers, but still experienced teachers as involved, showed moderate levels of engagement and made marginally significant gains in engagement across the school year. Perhaps surprisingly, these configural analyses also suggested that peer groups can dampen the effects of low involvement from teachers: Students who experienced their teachers as less involved, but who nevertheless affiliated with more engaged peers, also showed moderate levels of engagement and were able to maintain their engagement over the school year. Perhaps positive connections with peers have the potential, at least in the short run of a school year, to buffer some of the motivational costs otherwise associated with perceived lack of teacher support.

\section{Limitations and Future Directions}

It is important to consider the shortcomings of the current study, in terms of design and measurement, when interpreting its findings and making suggestions for further investigation of joint effects. In terms of design, the study is limited in that it focused on changes in engagement 
across only two time points within a single year. This made it impossible to follow the joint effects of teachers and peers across subsequent school years, as students encountered new teachers and joined new peer groups. Longer time frames with more measurement points would be useful if future studies aim to examine cumulative long-term effects or to explore meditational models, reciprocal effects, or growth curves. Previous studies of joint effects suggest that all of these processes are important targets (e.g., Wang \& Eccles, 2012).

In terms of measurement, the strategies used in the current study to assess student engagement and teacher involvement were limited in their ability to map the complex social world of teachers and peers during middle school. The use of multiple, independent reporters can be viewed as a strength of the study, but the decision to ask students about the involvement of "my teacher" as a proxy for the involvement of teachers in general may not fully capture the range of teacher interactions that students experience in middle school settings, where they typically encounter many teachers over the day. Although this strategy is common among researchers who assume that it is students' perceptions of experiences that are key to their engagement (e.g., DeLaet, et al., 2015; Furrer \& Skinner, 2003; Skinner \& Belmont, 1993), it is an empirical question whether findings from the current study will replicate in research utilizing aggregate indicators that, for example, are based on average involvement scores from every teacher with whom a student interacts. By the same token, reliance on homeroom teachers as the sole reporters of students' engagement, even teachers who indicated that they knew students well, may fall short of capturing the range of engagement that students exhibit from class to class over the day. Although teacher-reports of student engagement likely have advantages over selfreports (which were used in the majority of studies targeting joint teacher-peer effects), it is an 
empirical question whether the pattern of results found in the current study will replicate in research focused on other measures of engagement, such as classroom observations or aggregates that combine engagement ratings from multiple teachers.

Finally, the current study is limited in that it did not supplement longitudinal correlational findings by explicitly incorporating markers of potential mechanisms of joint influence. As previously discussed, a variety of mechanisms have been documented through which teachers influence student engagement and motivation (Sabol \& Pianta, 2012; Wentzel, 2009a) and studies are increasingly identifying pathways of peer influence, which seem to be both cognitive (for a review, see Brechwald \& Prinstein, 2011) and behavioral (Kandel, 1985; Sage \& Kindermann, 1999). Such evidence bolsters the current correlational findings, but causal interpretations would be strengthened by future studies that include measures of possible mechanisms to explain joint teacher-peer effects, and then test their viability using meditational analyses. Combined with experimental studies, such findings would help rule out alternative third variable explanations that are otherwise plausible. For example, students' behavioral problems may underlie both declines in their academic motivation and in the quality of their relationships with teachers (e.g., Wang \& Fredricks, 2014) and peers (Davidson et al., 2010). Future studies that directly examine potential mechanisms would begin to identify the (perhaps multiple) pathways through which peers and teachers jointly influence students' academic engagement.

\section{Implications for Future Research}

The current study is consistent with previous research examining the joint effects of peer and teacher relationships on the development of students' academic functioning, but also makes 
several key contributions to this growing area of study. First, findings suggest that, in addition to the features of peers already identified in other studies of joint teacher-peer effects, it would be useful to add peer groups, or more specifically, the motivational composition of peer groups, as another peer attribute that plays a role in students' engagement over and above that of teachers, and whose effects seem to be contextualized by teacher involvement. Second, findings from the current investigation corroborate the notion that using distinct sources of information about the three players in processes of joint effects (namely, peers, teachers, and student engagement) may make it easier to discern certain forms of contextualized effects. Third, it underscores some of the methodological strategies, like SCM, that may be useful in capturing the active ingredients in peer groups, and encourages researchers to consider re-analyzing their data sets, if they contain all the elements needed to meaningfully test for cumulative and contextualized joint effects.

Finally, the current study highlights the value of using an ecological perspective, as well as motivational and developmental theories like SDT and SEF, to frame expectations about joint influences. Ecological perspectives provide a larger framework within which to consider the influences of peer and teacher subsystems, and suggest conceptual terms, like cumulative and contextualized effects, to supplement researchers' reliance on statistical terms like additive and interactive. They open up a range of other kinds of contextualized effects and point to other subsystems, such as friendship networks, or family and neighborhood subsystems, to which these ideas could usefully be extended. More specific theories, like SDT, suggest that future work examining potential mechanisms should include students' sense of relatedness to peers and teachers, and examine whether they mediate the effects of peer group engagement and teacher 
involvement on changes in student engagement. SEF also suggests that particular kinds of contextualized effects, in which low teacher involvement contributes to differential susceptibility to peer groups, may represent an emergent developmental phenomenon, that only appears after the transition to middle school, when environmental shifts make it more difficult for students to connect with teachers (Eccles \& Roeser, 2009). Such conceptual considerations may be helpful to future studies in guiding the selection of peer characteristics and in making predictions about how and why their effects might (or might not) be contextualized by students' relationships with their teachers.

Models of joint teacher-peer effects. Future research on joint effects may also benefit from greater discussion of the different ways in which influences from peers and teachers can work together. The notion of differential susceptibility provides one hypothesis, in which the lack of close relationships with teachers renders students more open to peer group influences (Sabol \& Pianta, 2012), but alternative models that posit other kinds of contextualized effects, like compensatory or synergistic effects, could also be fruitful. It is important to note that these alternative models are not necessarily mutually exclusive; some are complementary. For example, in the present study, we found evidence that joint effects are both cumulative (i.e., additive) and contextualized (in this case, amplifying and dampening susceptibility). In other words, both teachers and peers are clearly important, in that support from one partner cannot fully substitute for poor relationships with the other, but each partner can still buffer or protect students from the worst motivational consequences of low levels of support from the other.

Of course, some models of contextualized effects are incompatible with cumulative models. For example, fully compensatory models, in which high levels of support from either 
partner are sufficient to produce the best outcomes, indicate that effects are not additive, instead they are substitutive - either one is a sufficient condition for the outcome. Other kinds of contextualized models also rule out additive effects, such as multiplicative threshold models in which some minimal level of support from one partner is required if the other partner is to have an impact. For example, if relationships with teachers are bad enough, it may be that no amount of peer encouragement can reignite students' engagement. Or, if a student's peer group is sufficiently disaffected, he or she may no longer respond to a teacher's involvement, support, or reassurance. These models suggest completely contextualized effects, where if one relationship is unfavorable enough, it can actually cancel the impact of the other social partner.

One strategy for discerning contextualized effects, employed in the current study as well as several previous ones (Davidson et al., 2010; Furrer \& Skinner, 2003; Raufelder et al., 2013), is the use of pattern-oriented or person-centered approaches that identify subgroups of students who inhabit qualitatively different peer-teacher niches, and comparing them on target outcomes, such as changes in motivational or academic functioning. The more that research on joint effects moves away from statistical models of interactive effects and toward conceptual models of contextualized effects, the wider the array of methodological strategies that can be brought to bear. In this regard, researchers may wish to take advantage of conceptual models and statistical techniques applied in work on developmental psychopathology (Luthar, Cicchetti, \& Becker, 2000) and environmental reactivity (e.g., Moore \& Depue, 2016), where researchers have considered hypotheses that include protective or buffering effects, immunization, thresholds, cumulative risk, diathesis-stress, and other forms of differential vulnerability or susceptibility to the environment (e.g., Ellis et al., 2011). 


\section{Reciprocal effects of student engagement on teachers and peers. As}

research increasingly focuses on social dynamics among multiple partners in the classroom, studies may also be expanded to include a consideration of reciprocal effects, in which students' own engagement feeds back to shape the supports they receive from teachers and peers. And, just as feedforward effects have been found to be contextualized, it is possible that reciprocal processes involving both social partners may also interact with each other. Engagement versus disaffection may turn out to be markers for whether students receive a double dose of motivational support or discouragement. That is, students who are highly engaged not only receive more involvement (as well as other forms of support) from teachers, but they also have access to more engaged groups of peers, whereas more disaffected students typically experience their teachers as withdrawing their support and becoming more controlling over time, while at the same time their peer connections are largely confined to other disaffected students (Kiuru et al., 2015; Nurmi \& Kiuru, 2015; Skinner \& Belmont, 1993). Future studies that examine joint effects over longer periods of time could explore whether such reciprocal feedback processes amplify the feedforward effects suggested by findings from the current study, potentially contributing to virtuous and vicious cycles that shape the development of student engagement and motivation over multiple school years.

\section{Implications for Practice}

Although the research base is too thin at the current time to allow for any definitive recommendations, findings from studies of joint effects suggest three possibilities for educators and researchers to consider in their efforts to refine practices and strengthen interventions designed to promote students' engagement and motivational development. First, it seems likely 
that interventions targeting either teachers or peers many exert their effects through two pathways. Cumulative and contextualized joint effects, such as the ones found in the current study, imply that improvements in connections with either partner (e.g., increasing connections with teachers or with engaged peers) should not only exert positive effects on engagement directly, but should also exert positive effects indirectly, by mitigating the worst impacts of problems with the other partner (e.g., low quality relationships with teachers or connections to disaffected peers). At the same time, however, studies of joint effects also suggest that interventions targeting only one social partner will not be sufficient to optimize student engagement over the long term. Results from this and other studies indicating contextualized effects imply that interventions focusing on a single classroom partner will only produce optimal engagement for a subset of students, namely, those who already have positive connections with the other partner. The students most in need of support, namely, highly disaffected students, will likely improve only in response to interventions that help them establish improved relationships with both involved teachers and engaged groups of peers.

Second, if the effects of peers are indeed contextualized, then interventions designed to improve student-teacher relationships may not only take on an added urgency, they may also benefit from an expanded focus. The sense of urgency follows from findings suggesting that low quality teacher relationships may pose a double risk for student motivation: once because of the direct impact of unsupportive teachers, and once because poor student-teacher relationships may leave students at the mercy of peer group influences, which are unlikely to be uniformly positive. According to studies of joint effects, it would be especially important for teachers to reach out to children and youth who affiliate with disaffected peers. If teachers can intentionally provide 
higher levels of involvement, such students may be protected from the worst effects of these connections. In the long run, teachers may develop strategies that are effective in bringing whole groups of disaffected peers back toward engagement, which would then allow all students access to groups of more engaged peers (Furrer, Skinner, \& Pitzer, 2014). Interventions to support teachers in these challenging tasks may be able to bolster their resolve by highlighting findings from studies such as the current one that make more explicit the "invisible hand of the teacher" in peer relationships (Kindermann, 2011).

Finally, findings from the current study may lead researchers, interventionists, and educators to a renewed appreciation of engagement, not only as a malleable motivational state that protects students from risky behaviors and contributes to their academic success, but also as an energetic resource that students themselves can offer their classmates. Adding to the list of peer attributes that predict motivational development, such as peer relatedness, kindness, emotional support, and instrumental help, the current study highlights the potential impact of joint activity with peers who are behaviorally and emotionally engaged (Wentzel et al., 2010). Such interactions may help to sustain or rekindle students' own enthusiastic participation in learning activities. The more that theories and research can succeed in capturing the interplay among interaction partners in the complex social ecology of the school, the more helpful they will be to educators and interventionists dedicated to the hard work of optimizing students' engagement, motivation, and academic development. 


\section{References}

Altermatt, E. R., \& Pomerantz, E. M. (2005). The implications of having high-achieving versus low-achieving friends: A longitudinal analysis. Social Development, 14, 61-81. doi:10.1111/j.1467-9507.2005.00291.x

Anderman, L. H., \& Anderman, E. M. (1999). Social predictors of changes in students' achievement goal orientations. Contemporary Educational Psychology, 24, 21-37. doi:10.1006/ceps.1998.0978.

Anderson, A. R., Christenson, S. L., Sinclair, M. F., \& Lehr, C. A. (2004). Check \& Connect: The importance of relationships for promoting engagement with school. Journal of School Psychology, 42, 95-113. doi:10.1016/j.jsp.2004.01.002

Arbuckle, J. L. (2010). Amos (Version 19.0) [Computer Program]. Chicago, IL: SPSS.

Berndt, T., Hawkins, J., \& Jiao, Z. (1999). Influences of friends and friendships on adjustment to junior high school. Merrill-Palmer Quarterly, 45, 13-41.

Blondal, K. S., \& Adalbjarnardottir, S. (2012). Student disengagement in relation to expected and unexpected educational pathways. Scandinavian Journal of Educational Research, 56, 85-100. doi:10.1080/00313831.2011.568607

Brechwald, W. A., \& Prinstein, M. J. (2011). Beyond homophily: A decade of advances in understanding peer influence processes. Journal of Research on Adolescence, 21, 166-179. doi:10.1111/j.1532-7795.2010.00721.x

Bronfenbrenner, U. (1976). The experimental ecology of education. Paper presented at the annual meetings of the American Educational Research Association, San Francisco, CA.

Bronfenbrenner, U., \& Morris, P.A. (2006). The bioecological model of human development. In 
R. Lerner \& W. Damon (Eds.), Handbook of child psychology: Volume 1, Theoretical models of human development ( $6^{\text {th }}$ ed.; pp. 793-828), Hoboken, NJ; Wiley.

Cairns, R. B., \& Cairns, B. D. (1994). Lifelines and risks: Pathways of youth in our time. New York: Cambridge University Press.

Cairns, R. B., Perrin, J. E., \& Cairns, B. D. (1985). Social structure and social cognition in early adolescence: Affiliative patterns. Journal of Early Adolescence, 5, 339-355.

Connell, J. P., \& Wellborn, J. G. (1991). Competence, autonomy and relatedness: A motivational analysis of self-system processes. In M. Gunnar \& L. A. Sroufe (Eds.), Minnesota Symposium on Child Psychology: Vol. 23. Self processes in development (pp. 43-77). Chicago: University of Chicago Press.

Danielsen, A. G., Wiium, N., Wilhelmsen, B. U., \& Wold, B. (2010). Perceived support provided by teachers and classmates and students' self-reported academic initiative. Journal of School Psychology, 48, 247-267.

Davidson, A. J., Gest, S. D., \& Welsh, J. A. (2010). Relatedness with teachers and peers during early adolescence: an integrated variable-oriented and person-oriented approach. Journal of School Psychology, 48, 483-510. doi:10.1016/j.jsp.2010.08.002

Deci, E. L. (1992). On the nature and function of motivational theories. Psychological Science, 3, 167-171.

Deci, E. L., \& Ryan, R. M. (1985). Intrinsic motivation and self-determination in human behavior. New York: Plenum Press.

De Laet, S., Colpin, H., Vervoort, E., Doumen, S., van Leeuwen, K., Goossens, L., \& Verschueren, K. (2015). Developmental trajectories of children's behavioral engagement in 
late elementary school: Both teachers and peers matter. Developmental Psychology, 51, 1292-1306.

Eccles, J. S., \& Roeser, R. W. (2009). Schools, academic motivation, and stage-environment fit. R.M, Lerner \& L. Steinberg (Eds.) Handbook of adolescent psychology: Vol. 1. Individual bases of adolescent development ( $3^{\text {rd }}$ edition, pp. 404-434). Hoboken, NJ: Wiley.

Eccles. J. S., Midgley, C., Wigfield, A., Buchanan, C. M., Reuman, D., Flanagan, C., \& McIver, D. (1993). Development during adolescence: The impact of stage-environment fit on adolescents' experiences in schools and families. American Psychologist, 48, 90-101.

Ellis, B. J., Boyce, W. T., Belsky, J., Bakermans-Kranenburg, M. J., \& Van IJzendoorn, M. H. (2011). Differential susceptibility to the environment: An evolutionaryneurodevelopmental theory. Development and Psychopathology, 23, 7-28. doi:10.1017/S0954579410000611.

Fall, A. M., \& Roberts, G. (2012). High school dropouts: Interactions between social context, self-perceptions, school engagement, and student dropout. Journal of adolescence, 35, 787-798. doi:10.1016/j.adolescence.2011.11.004

Finn, J. D. (1989). Withdrawing from school. Review of Educational Research, 59, 117-142. doi:10.3102/00346543059002117

Finn, J. D., \& Zimmer, K. S. (2012). Student engagement: What is it? Why does it matter?. In Handbook of research on student engagement (pp. 97-131). Springer US. doi: 10.1007/978$1-4614-2018-7 \_5$

Furrer, C., \& Skinner, E. A. (2003). Sense of relatedness as a factor in children's academic engagement and performance. Journal of Educational Psychology, 95, 148-162. 
Furrer, C. J., Skinner, E. A., \& Pitzer, J. R. (2014). The influence of teacher and peer relationships on students' classroom engagement and everyday resilience. In D. J. Shernoff \& J. Bempechat (Eds.), National Society for the Study of Education Yearbook. Engaging Youth in Schools: Empirically-Based Models to Guide Future Innovations, vol. 113, (pp. 101-123). Columbia University: Teachers's College.

Goodenow, C. (1993). Classroom belonging among early adolescent students: Relationships to motivation and achievement. Journal of Early Adolescence, 13, 21-43.

Hallinan, M. T., \& Williams, R. A. (1990). Students' characteristics and the peer-influence process. Sociology of Education, 63, 122-132. doi:10.2307/2112858

Hamre, B. K., \& Pianta, R. C. (2001). Early teacher-child relationships and the trajectory of children's school outcomes through eighth grade. Child Development, 72, 625-638. doi:10.1111/1467-8624.00301

Harris, J. R. (1995). Where is the child's environment? A group socialization theory of development. Psychological Review, 102, 458 - 489.

Hughes, J., \& Kwok, O. (2007). Influence of student-teacher and parent-teacher relationships on lower achieving readers' engagement and achievement in the primary grades. Journal of Educational Psychology, 99, 39-51. doi:10.1037/0022-0663.99.1.39

Kandel, D. B. (1985). On processes of peer influences of adolescent drug use: A developmental perspective. Advances in Alcohol and Substance Use, 4, 139-163.

Kindermann, T. A. (1993). Natural peer groups as contexts for individual development: The case of children's motivation in school. Developmental Psychology, 29, 970 - 977. 
Kindermann, T. A. (1996). Strategies for the study of individual development within naturally-existing peer groups. Social Development, 5, 158-173.

Kindermann, T. A. (2003). Development of children's social relationships. In J. Valsiner \& K. Connolly (Eds.), Handbook of developmental psychology (pp. 407 - 430). Thousand Oaks, CA: Sage.

Kindermann, T. A. (2007). Effects of naturally existing peer groups on changes in academic engagement in a cohort of sixth graders. Child Development, 78, 1186-1203. doi:10.1111/j.1467-8624.2007.01060.x

Kindermann, T. A. (2011). Commentary: The invisible hand of the teacher. Journal of Applied Developmental Psychology 32, 304-308.

Kindermann, T. A, \& Skinner, E. A. (2012). Will the real peer group please stand up? A "tensegrity" approach to examining the synergistic influences of peer groups and friendship networks on academic development. In F. Pajares \& T. Urdan (Series Eds.), Adolescents and Education, A. Ryan \& G. Ladd (Volume Eds.), Peer Relationships and Adjustment at School (pp. 51-78). New York: Information Age Publishing.

Kiuru, N., Aunola, K., Lerkkanen, M. K., Pakarinen, E., Poskiparta, E., Ahonen, T., A. Poikkeus, \& Nurmi, J. E. (2015). Positive teacher and peer relations combine to predict primary school students' academic skill development. Developmental psychology, 51, $434-446$.

Klem, A. M., \& Connell, J. P. (2004). Relationships matter: Linking teacher support to student engagement and achievement. The Journal of school health, 74, 262-273. doi:10.1111/j.1746-1561.2004.tb08283.x

Kline, R. B. (2011). Principles and practice of structural equation modeling. New York: 
PEER INFLUENCE ON STUDENT ENGAGEMENT

Guilford Press.

Kurdek, L. A., \& Sinclair, R. J. (2000). Psychological, family, and peer predictors of academic outcomes in first-through fifth-grade children. Journal of Educational Psychology, 92, 449457.

doi:10.1037/0022-0663.92.3.449

Ladd, G. W. (1990). Having friends, keeping friends, making friends, and being liked by peers in the classroom: Predictors of children's early school adjustment? Child Development, 61, $1081-1100$.

doi:10.1111/j.1467-8624.1990.tb02843.x

Lempers, J. D., \& Clark-Lempers, D. S. (1992). Young, middle, and late adolescents' comparisons of the functional importance of five significant relationships. Journal of youth and adolescence, 21, 53-96. doi: 10.1007/BF01536983

Li, Y., \& Lerner, R. M. (2011). Trajectories of school engagement during adolescence: implications for grades, depression, delinquency, and substance use. Developmental Psychology, 47, 233-247. doi:10.1037/a0021307

Libbey, H. P. (2004). Measuring student relationships to school: Attachment, bonding, connectedness, and engagement. Journal of school health, 74(7), 274-283.

Little, T. D., Bovaird, J. A., \& Widaman, K. F. (2006). On the merits of orthogonalizing powered and product terms: Implications for modeling interactions among latent variables. Structural Equation Modeling, 13, 497-519. doi: 10.1207/s15328007sem1304_1

Luthar, S. S., Cicchetti, D., \& Becker, B. (2000). The construct of resilience: A critical evaluation and guidelines for future work. Child Development, 71, 543-562. 
PEER INFLUENCE ON STUDENT ENGAGEMENT

doi:10.1111/1467-8624.00164

Lynch, A. D., Lerner, R. M., \& Leventhal, T. (2013). Adolescent academic achievement and school engagement: An examination of the role of school-wide peer culture. Journal of youth and adolescence, 42, 6-19. doi:10.1007/s10964-012-9833-0

Martin, A. J., \& Dowson, M. (2009). Interpersonal relationships, motivation, engagement, and achievement: Yields for theory, current issues, and educational practice. Review of educational research, 79(1), 327-365. doi:10.3102/0034654308325583

Moore, S. R., \& Depue, R. A. (2016). Neurobehavioral foundation of environmental reactivity. Psychological Bulletin, 142, 107-164. doi:10.1037/bul0000028

Muthén, L.K. \& Muthén, B.O. (2012). Mplus user's guide: Seventh Edition. Los Angeles, CA: Muthén \& Muthén.

Nelson, R. M., \& DeBacker, T. K. (2008). Achievement motivation in adolescents: the role of peer climate and best friends. The Journal of Experimental Education, 76, 170-189. doi:10.3200/JEXE.76.2.170-190

Newmann, F. M. (Ed.) (1992). Student engagement and achievement in American secondary schools. New York: Teachers College Press.

Nurmi, J. E., \& Kiuru, N. (2015). Students' evocative impact on teacher instruction and teacherchild relationships Theoretical background and an overview of previous research. International Journal of Behavioral Development, 39, 445-457. doi:10.1177/0165025415592514

Nylund, K. L., Asparouhov, T., \& Muthén, B. O. (2007). Deciding on the number of classes in latent class analysis and growth mixture modeling: A Monte Carlo simulation study. 
PEER INFLUENCE ON STUDENT ENGAGEMENT

Structural equation modeling, 14, 535-569.

Osterman, K. F. (2000). Students' need for belonging in the school community. Review of Educational Research, 70, 323-367.

Quin, D. (in press). Longitudinal and contextual associations between teacher-student relationships and student engagement: A systematic review. Review of Educational Research, doi:10.3102/0034654316669434.

Raufelder, D., Jagenow, D., Drury, K., \& Hoferichter, F. (2013). Social relationships and motivation in secondary school: Four different motivation types. Learning and Individual Differences, 24, 89-95. doi: 10.1016/j.lindif.2012.12.002

Reeve, J. (2012). A self-determination theory perspective on student engagement. In S. L. Christenson, A. L. Reschly, \& C. Wylie (Eds.), Handbook of research on student engagement (pp. 149-172). New York: Springer.

Roeser, R. W., Eccles, J. S., \& Sameroff, A. J. (2000). School as a context of early adolescents' academic and social-emotional development: A summary of research findings. The Elementary School Journal, 100, 443-471. doi:10.1086/499650

Rumberger, R. W., \& Rotermund, S. (2012). The relationship between engagement and high school dropout. In S. L. Christenson, A. L. Reschly, \& Wylie, C. (Eds.), Handbook of research on student engagement (pp. 491-514). New York, NY: Springer.

Ryan, A. M. (2000). Peer groups as a context for the socialization of adolescents' motivation, engagement, and achievement in school. Educational Psychologist, 35, 101-111. doi:10.1207/S15326985EP3502_4

Ryan, A. M. (2001). The peer group as a context for the development of young adolescent 
PEER INFLUENCE ON STUDENT ENGAGEMENT

motivation and achievement. Child Development, 72, 1135-1150.

doi:10.1111/1467-8624.00338

Ryan, A. M., \& Shin, H. (2011). Help-seeking tendencies during early adolescence: An examination of motivational correlates and consequences for achievement. Learning and Instruction, 21, 247-256. doi:10.1016/j.learninstruc.2010.07.003

Ryan, R. M., \& Deci, E. L. (2009). Promoting self-determined school engagement: Motivation, learning, and well-being. In K. R. Wentzel \& A. Wigfield (Eds), Handbook of motivation at school (pp. 171-195). Routledge: New York: NY.

Sabol, T. J., \& Pianta, R. C. (2012). Recent trends in research on teacher-child relationships. Attachment \& Human Development, 14(3), 213-231. doi:10.1080/14616734.2012.672262

Sage, N. A., \& Kindermann, T. A. (1999). Peer networks, behavior contingencies, and children's engagement in the classroom. Merrill-Palmer Quarterly, 454, 143-171.

Shernoff, D. J., Csikszentmihalyi, M., Schneider, B., \& Shernoff, E. S. (2003). Student engagement in high school classrooms from the perspective of flow theory. School Psychology Quarterly, 18, 158-176. doi:10.1521/scpq.18.2.158.21860

Skinner, E. A. (2016). Engagement and disaffection as central to processes of motivational resilience and development. In K.R. Wentzel \& D.B. Miele (Eds), Handbook of motivation at school (pp. 145-168). Routledge: New York: NY.

Skinner, E. A., \& Belmont, M. J. (1993). Motivation in the classroom: Reciprocal effects of teacher behavior and student engagement across the school year. Journal of Educational Psychology, 85, 571-581. doi:10.1037/0022-0663.85.4.571

Skinner, E. A., Kindermann, T. A., Connell, J. P., \& Wellborn, J. G. (2009). Engagement and 
disaffection as organizational constructs in the dynamics of motivational development. In K. Wentzel \& A. Wigfield (Eds.), Handbook of motivation at school (pp. 223-245), Routledge.

Skinner, E. A., Kindermann, T. A., \& Furrer, C. (2008). A motivational perspective on engagement and disaffection: Conceptualization and assessment of children's behavioral and emotional participation in academic activities in the classroom. Educational and Psychological Measurement, 69, 493-525. doi:10.1177/0013164408323233

Skinner, E. A., Wellborn, J. G., \& Connell, J. P. (1990). What it takes to do well in school and whether I've got it: A process model of perceived control and children's engagement and achievement in school. Journal of Educational Psychology, 82, 22-32. doi:10.1037/00220663.82 .1 .22

Skinner, E. A., Zimmer-Gembeck, M. J., Connell, J. P. (1998). Individual differences and the development of perceived control. Monographs of the society for Research in Child Development, 63, i-231. doi:10.2307/1166220

Tabachnick, B. G., \& Fidell, L. S. (2007). Using Multivariate Statistics (5th ed.). New York: Allyn and Bacon.

Ullah, H., Wilson, M.A. (2007). Students' academic success and its association to student involvement with learning and relationships with faculty and peers. College Student Journal, 41, 1192-1202.

Wang, M. T., \& Degol, J. (2014). Staying engaged: Knowledge and research needs in student engagement. Child Development Perspectives, 8(3), 137-143.

Wang, M., Eccles, J.S. (2012). Social support matters: Longitudinal effects of social support on 
PEER INFLUENCE ON STUDENT ENGAGEMENT

three dimensions of school engagement from middle to high school. Child

Development, 83, 877-895. doi: 10.1111/j.1467-8624.2012.01745.x

Wang, M., Fredricks, J. (2014). The reciprocal links between school engagement, youth problem behaviors, and school dropout during adolescence. Child Development, 85, 722-737. doi: $10.1111 /$ cdev. 12138

Wang, M., \& Peck, S. C. (2013). Adolescent educational success and mental health vary across school engagement profiles. Developmental Psychology, 49, 1266-1276. doi:10.1037/a0030028

Weiner, B. (1990). History of motivational research in education. Journal of Educational Psychology, 82, 616-622.

Wellborn, J. (1992). Engaged and disaffected action: The conceptualization and measurement of motivation in the academic domain. Unpublished Dissertation, Department of Psychology, University of Rochester, Rochester, NY.

Wentzel, K. R. (1994). Relations of social goal pursuit to social acceptance, classroom behavior, and perceived social support. Journal of Educational Psychology, 86, 173-182. doi:10.1037/0022-0663.86.2.173

Wentzel, K. R. (1997). Student motivation in middle school: The role of perceived pedagogical caring. Journal of Educational Psychology, 89, 411- 418. doi:10.1037/0022-0663.89.3.411

Wentzel, K. R. (1999). Social-motivational processes and interpersonal relationships: Implications for understanding motivation at school. Journal of Educational Psychology, 91, 76- 97. doi:10.1037/0022-0663.91.1.76

Wentzel, K. R. (2009a). Students' relationships with teachers as motivational contexts. In K. 
Wentzel \& A. Wigfield (Eds.), Handbook of Motivation at School (pp. 301-322).

Routledge.

Wentzel, K. R. (2009b). Peers and academic functioning at school. In K. Rubin, W. Bukowski, \& B. Laursen (Eds.), Handbook of peer interactions, relationships, and groups. Social, emotional, and personality development in context (pp. 531-547). New York: Guilford Press.

Wentzel, K. R., \& Miele, D. (2016). (Eds.), Handbook of motivation at school (2 ${ }^{\text {nd }}$ edition). Malwah, NJ: Erlbaum.

Wentzel, K. R., \& Muenks, K. (2016). Peer influence on students' motivation, academic achievement, and social behavior. In K. Wentzel \& G. Ramani (Eds.), Handbook of Social Influences in School Contexts: Social-Emotional, Motivation, and Cognitive Outcomes (pp. 13-30). New York: Routledge.

Wentzel, K. R., Battle, A., Russell, S. L., \& Looney, L. B. (2010). Social supports from teachers and peers as predictors of academic and social motivation. Contemporary Educational Psychology, 35, 193-202. doi:10.1016/j.cedpsych.2010.03.002

Wentzel, K. R., \& Ramani, G. B. (Eds.) (2016), Handbook of social influences in school contexts: Social-emotional, motivation, and cognitive outcomes. New York, NY: Routledge.

Wentzel, K. R., \& Watkins, D. E. (2011). Instruction based on peer interactions. In R.E. Mayer \& P.A. Alexander (Eds.) Handbook of research on learning and instruction (pp.322-343). New York: Routledge.

Wigfield, A., Eccles, J. S., Fredricks, J. A., Simpkins, S., Roeser, R., \& Schiefele, U. (2015). Development of achievement motivation and engagement. In R. M. Lerner (Series Ed.) \& 
M. Lamb (Volume Ed.), Handbook of child psychology and developmental

science, $7^{\text {th }}$ Ed. Vol.3. Socioemotional processes (pp. 657-700). New York: John Wiley. 
Table 1.

Construct Means, Standard Deviations, and Correlations.

\begin{tabular}{|c|c|c|c|c|c|c|c|c|c|}
\hline & 1 & 2 & 3 & 4 & 5 & 6 & 7 & $m$ & $S D$ \\
\hline 1. Student Engagement Fall & - & & & & & & & 3.07 & .57 \\
\hline 2. Student Engagement Spring & $.75^{* * *}$ & - & & & & & & 3.07 & .61 \\
\hline 3. Peer Engagement Fall & $.42^{* * *}$ & $.39^{* * *}$ & - & & & & & 3.09 & .34 \\
\hline 4. Teacher Involvement & $.34^{* * *}$ & $.40^{* * *}$ & $.20^{* * *}$ & - & & & & 3.01 & .52 \\
\hline 5. Sex & $.16^{* *}$ & $.21^{* * *}$ & $.19^{* * *}$ & $.29^{* * *}$ & - & & & 1.47 & .50 \\
\hline 6. Group Stability & $.17^{*}$ & $.17^{*}$ & .03 & $.10^{\dagger}$ & $.20^{* * *}$ & - & & .46 & .33 \\
\hline 7. Group Size & $.19^{* * *}$ & .08 & $.25^{* * *}$ & $.10^{\dagger}$ & $.27^{* * *}$ & $.13^{*}$ & - & 4.81 & 3.99 \\
\hline
\end{tabular}

Note. $N=366 . * * * p<.001 * * p<.01 * p<.05 \dagger p<.07$. 
Table 2.

Mean Level Differences Between Students with High or Low Teacher Involvement.

\begin{tabular}{|c|c|c|c|c|c|c|c|}
\hline & \multicolumn{2}{|c|}{$\begin{array}{l}\text { High Teacher } \\
\text { Involvement }\end{array}$} & \multicolumn{2}{|c|}{$\begin{array}{l}\text { Low Teacher } \\
\text { Involvement }\end{array}$} & \multirow[b]{2}{*}{$M_{\text {diff }}$} & \multirow[b]{2}{*}{$t$} & \multirow[b]{2}{*}{$p$} \\
\hline & $M$ & $S D$ & $M$ & $S D$ & & & \\
\hline Student Eng. Fall & 3.29 & .53 & 2.85 & .58 & -.44 & -6.32 & $<.001$ \\
\hline Student Eng. Spring & 3.32 & .55 & 2.76 & .61 & -.55 & -7.62 & $<.001$ \\
\hline Peer Engagement Fall & 3.18 & .33 & 3.02 & .35 & -.16 & -3.83 & $<.001$ \\
\hline Peer Group Size & 5.57 & 3.99 & 4.94 & 4.20 & -.64 & -1.24 & $>.05$ \\
\hline Peer Stability & .50 & .34 & .44 & .33 & -.06 & -1.42 & $>.05$ \\
\hline
\end{tabular}

Note. $n=129$ for the high teacher involvement group. $n=127$ for the low teacher involvement group. 
Table 3.

Latent Profile Analysis Model Fit Results.

\begin{tabular}{llll}
\hline & \multicolumn{3}{l}{ Statistical Criteria } \\
\cline { 2 - 4 } & AIC & BIC & Adj. BIC \\
\hline 2-profile Model & 1102.421 & 1129.739 & 1107.531 \\
3-profile Model & 1053.001 & 1095.93 & 1061.032 \\
4-profile Model & $\mathbf{1 0 2 9 . 0 8 8}$ & $\mathbf{1 0 8 7 . 6 2 7}$ & $\mathbf{1 0 4 0 . 0 3 8}$ \\
5-profile Model & 1024.618 & 1098.768 & 1038.489
\end{tabular}

Note $. \mathrm{AIC}=$ Akaike Information Criteria, $\mathrm{BIC}=$ Bayesian Information Criteria, $\mathrm{Adj} . \mathrm{BIC}=$ sample-size adjusted Bayesian Information Criteria $\left(n^{*}=(n+2) / 24\right)$. Lower AIC, BIC, and Adj. BIC values indicate better fit. Indices of fit for the chosen model appear in bold. The 5-profile model was removed from consideration because it identified profiles of inadequate size $(n<10)$. 
Figure 1.

The Interplay Between Peer and Teacher Influences on Changes in Students' Academic Engagement.

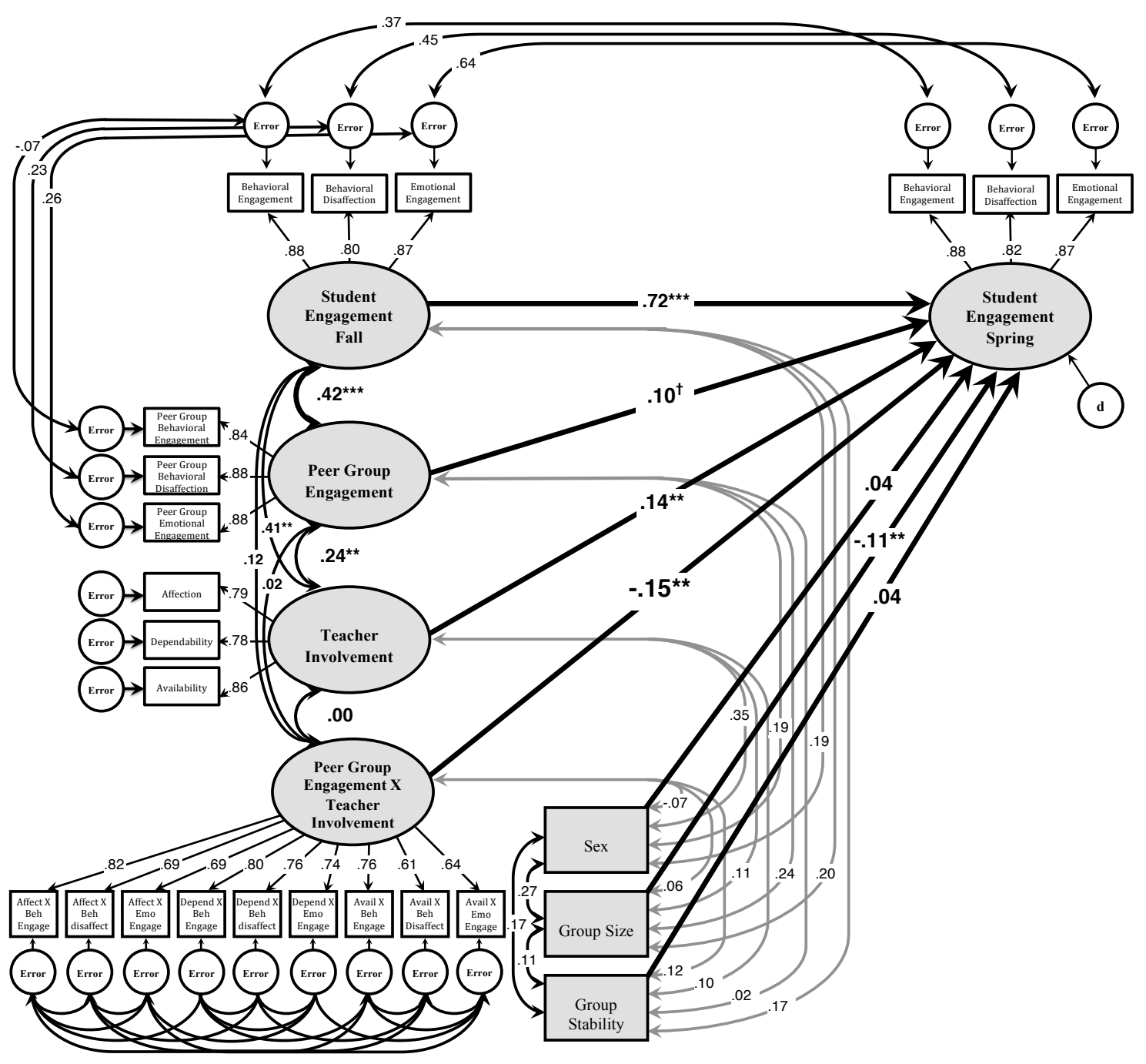

Note. $\chi^{2}(203)=188.302, p=.763 ; \mathrm{CMIN} / \mathrm{DF}=.928 ; \mathrm{CFI}=1.000 ; \mathrm{RMSEA}=.000 ; 90 \%$ confidence interval $=$ .000 to $.017 .{ }^{* * *} p<.001,{ }^{* *} p<.01, * p<.05+p<.07$. 
Figure 2.

Comparison of Peer Influence Between Students Who Perceive Teachers as Highly Involved and Students Who Perceive Teachers as Least Involved.

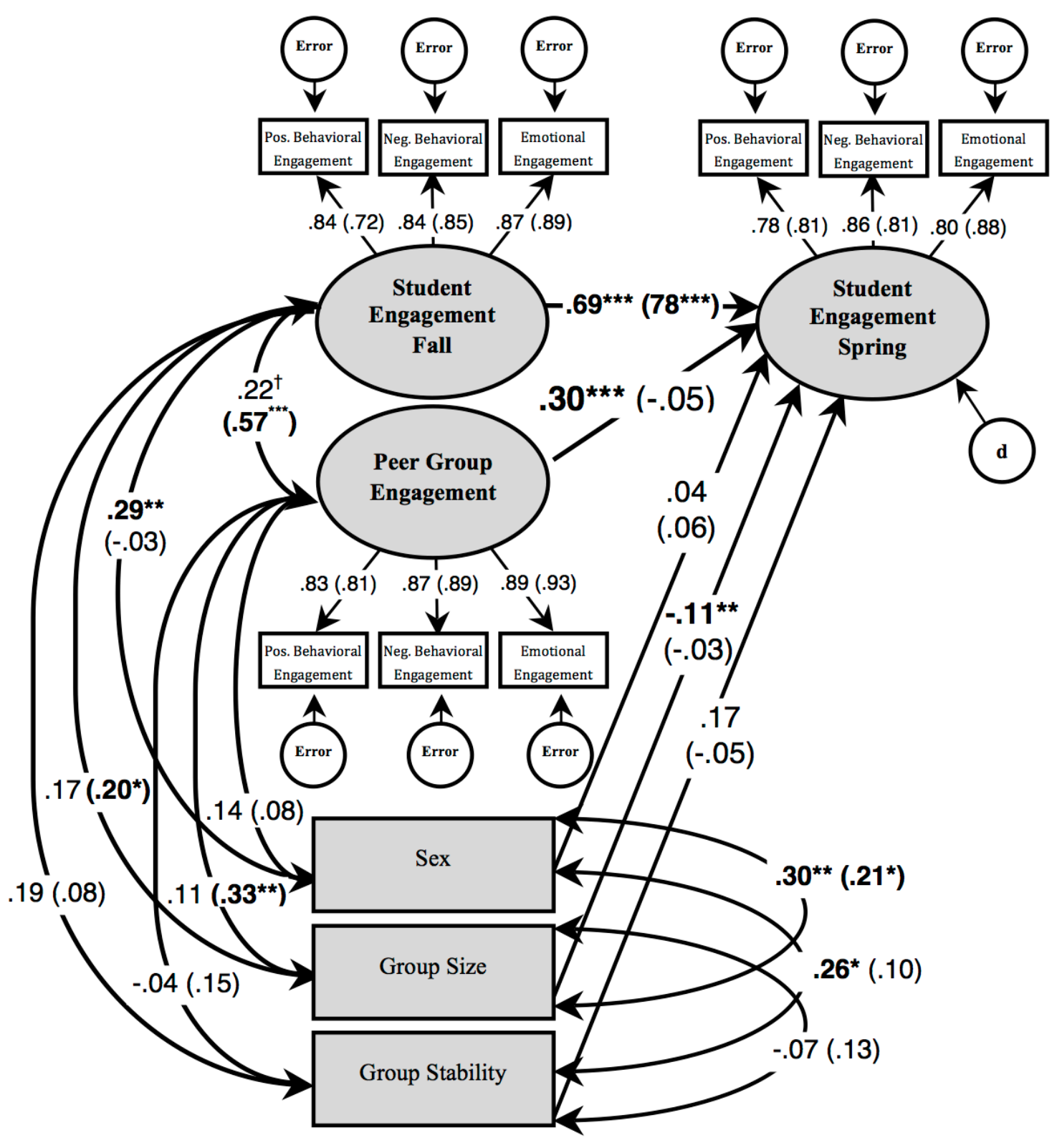

Note. $\chi^{2}(72)=90.632, p=.068 ; \mathrm{CMIN} / \mathrm{DF}=1.259 ; \mathrm{CFI}=.987$; RMSEA $=.032 ; 90 \%$ C.I. $=.000$ to .051 . The model parameters for students who experienced their teacher as highly involved appear in parentheses. Error correlations have been omitted from the figure for clarity. ${ }^{* * *} p<.001, * * p<.01, * p<.05, \dagger<.07$. 
Figure 3.

Differential Growth of Students' Academic Engagement Based on Students' Combined Experiences of Teacher Involvement and Peer Group Engagement.

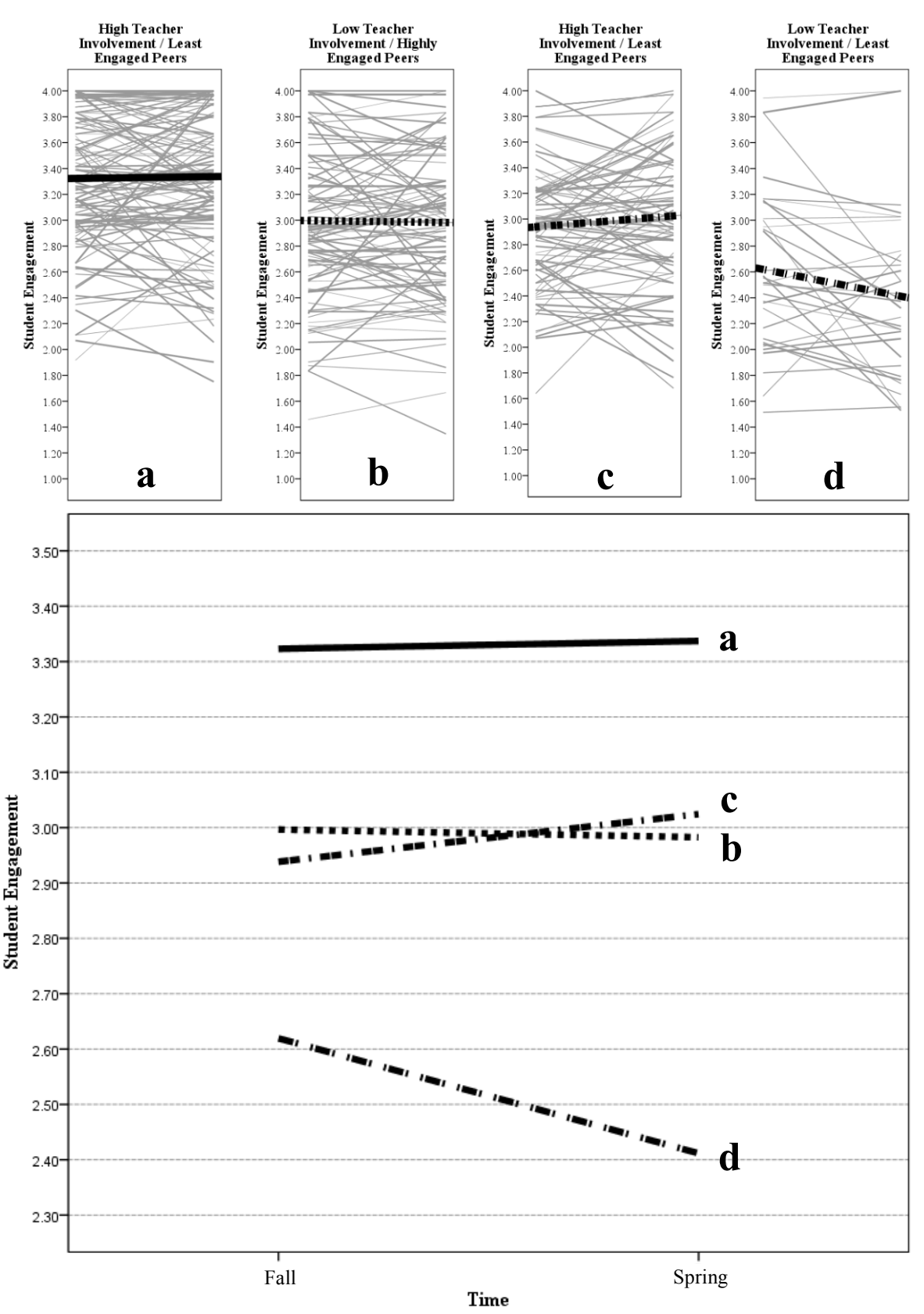

Note. Non-significant engagement changes in academic engagement are shown for students who (a) affiliate with highly engaged peer and experience high teacher involvement $(n=132)$, and who (b) affiliate with highly engaged peers and experience low teacher involvement $(n=107)$. Gains in engagement shown for students who (c) affiliate with least engaged peers and experience high teacher involvement $(n=94$; average increase marginally significant at $\mathrm{p}<.06)$. Significant decreases in engagement shown for students who (d) affiliate with least engaged peers and experience low teacher involvement $(n=33$; average decreases significant at $\mathrm{p}<.05)$. 